\section{Darwin's gradualism and empiricism}

SIR - In his recent Commentary, Rhodes ${ }^{1}$ details how Darwin "specifically repudiated" three of the four tenets attributed to Darwinian gradualism by Eldredge and Gould?', architects of the hypothesis of evolution by "punctuated equilibrium". The fourth tenet is "shared in substance by all who accept the fact of evolution". Rhodes further shows that Darwin subscribed to "both of the two important consequences of punctuated equilibrium."

It is surprising, then, that Rhodes concludes: "The hypothesis of punctuated equilibrium is of major importance for palaeontological theory and practice. Several significant tenets of this view were enunciated by Darwin . . . [but] it would be misleading to imply that he anticipated every nuance of the theory."

Which nuances were unanticipated by Darwin? How is saltational "punctuated equilibrium" different from Darwin's gradualism? Eldredge and Gould ${ }^{2}$ represent (misrepresent) gradualism as the equivalent of orthogenesis ${ }^{3}$. Now Rhodes has shown that Darwin's gradualism is very similar to "punctuated equilibrium" in outward appearance. However, gradualism and any form of saltation differ fundamentally in theory, and this difference deserves discussion.

A gradual process advances by steps, and intermediates are present as evidence of transition. Darwin's gradualism reflects a commitment to empiricism, commitment to the idea that suggested evolutionary transitions should be represented by evidence. Saltational "punctuated equilibrium" postulates how speciation takes place, based not on empirical evidence but on negative evidence - gaps in the fossil record. "Punctuated equilibrium is unscaled, and by nature untestable. It hardly deserves recognition as a conjecture of "major importance for palaeontological theory and practice". Palaeontology, like other scientific disciplines, is dedicated to the principle of empirical testability: hypotheses that cannot be tested are of little value in science.

\section{Museum of Paleontology,}

Phil.ip D. Gingerich

\section{The University of Michigan,}

Ann Arbor, Michigan 48109, USA

\footnotetext{
Rhodes, F.H.T. Nature 305, 269.272 (1983)

. Eldredge, N. \& (ivuld, S.J. in Models in Paleobiology (ed. T.J.M. Schopf) 82-115 (treeman, San Francisco , 1972). Penny, D Nalure 307, 8 (1984).
}

- Rhodes replies - My recent article ${ }^{1}$ showed that three of the four tenets of "pure gradualism" attributed to Darwin 2, were, in fact, repudiated by him and that his view of transmutation embraced the major tenets and consequences of what we now call "punctuated equilibrium."'

With that, and with the forty-six paragraphs required to demonstrate it, Gingerich agrees. It is with only the penultimate paragraph of my article that Dr Gingerich disagrees. Two questions are involved.

(1) Gingerich questions my description of punctuated equilibrium as a hypothesis of "major importance for palaeontological theory and practice". Webster defines a hypothesis as "a tentative assumption made in order to draw out and test its logical or empirical consequences". This is precisely what the hypothesis of punctuated equilibrium has done. It has provoked adulation and anger but it has also stimulated a remarkable flurry of detailed analytical studies designed to test the hypothesis. These range from fossil hominids ${ }^{3}$ to Ordovician trilobites ${ }^{4}$, Pennsylvanian gastropods $^{5}$, Mesozoic ${ }^{6}$ and Cenozoic molluscs $^{7.9}$, radiolarians ${ }^{10}$ and pollen ${ }^{11}$. The stimulus provided by the hypothesis to the study of its possible consequences in living organisms has been no less fruitful, including, for example, the evolutionary relationships of frogs $^{12}$, mimetic butterflies $^{13}$ and patterns of behaviour ${ }^{14}$. It continues to generate intense debate concerning the possibility of testing the hypothesis against the fossil record ${ }^{15}$ and the nature of the evolutionary process itself ${ }^{16,17}$.

If the test of a "major hypothesis" is that it stimulates major debate and testing of its logical or empirical consequences, the hypothesis of punctuated equilibrium surely qualifies.

I do not argue here for the validity of punctuated equilibrium: I do not argue for its distinctiveness - or lack of it - within a continuum of populations: I do not argue for the adequacy of the fossil evidence available to validate the hypothesis: I do not argue that it meets the canon of "empirical testability". All of these deserve continuing discussion. But I do argue that punctuated equilibrium - whether true or false - is a "hypothesis of major importance" and that it has had a beneficial impact on the quality of recent palaeontological studies.

(2) Gingerich asks, "Which nuances [of punctuated equilibrium] were unanticipated by Darwin?' 'From a long list, I suggest the following: its relationship to the genetics of stasis and of punctuation ${ }^{18}$, morphological stasis and developmental constraints $^{19}$, evolutionary models in relation to palaeoecology ${ }^{20}$, stratigraphical correlation $^{21}$, species selection ${ }^{22}$, mathematical models of evolutionary rates ${ }^{23}$, selection of RNA molecules ${ }^{24}$, phylogenetic divergence ${ }^{25}$, the molecular basis of adaptation $^{26}$, and the evolution of communities $^{27}$. These topics, and many more studied from the viewpoint of punctuated equilibrium, have been the subject to recent papers.

Although Darwin could scarcely have been expected to anticipate such nuances of these, the remarkable thing is that he did recognize and accept the major components of the present hypothesis of punc- tuated equilibrium. (So also did Simpson $^{28}$, whose contribution has been too little recognized in the current debate.) But to suggest that there was no nuance of punctuated equilibrium which was "unanticipated by Darwin" is to make an icon of Darwin and to adopt an extravagantly Whiggish view of the history of science of Darwin's particular contribution - great as that was.

Office of the President,

F.H.T. RHODES

Cornell University.

Ithaca, New York 14853, USA

1. Rhodes, F.H.T. Nature 305, 269-272 (1983).

2 Gould, S.J. \& Eldredge, N. Paleobiology 3, 115-155 (1977)

3. Cronin, J.E., Boas, N.T., Stringer, C.B. \& Rak, Y. Nature 292, 113-122 (1981)

4. Cisne, J.L., Chandlee, G.O., Rabe, B.D. \& Cohen, J.A Science 209, $925-927$ (1980)

5. Schindel, D.E. Bull. Geol. Soc. Am. 93, 400-408 (1982).

6. Hallam, A. Paleobiology 8, 354-366 (1982).

7. Kelley, P.H. J. Paleontol. 57, $581-598$ (1983).

8. Williamson, P.G. Nature 293, 437-443 (1981)

9. Shapiro, E.A. Abstr. Prog geol. Soc. Am. 10, 490 (1978).

10. Kellogg. D.E. in 3rd American Paleontological Convention: Proc. Vol. 1 (eds Mamet, B. \& Copeland M J.) 281-284 (1982)

11. Nichols, D.J. Palynology 6, 288-289 (1982)

12. Lynch, J.D. Systematic Zool. 31, 166-179 (1982).

13. Turner, J.R.G. Biol. J. Linn. Soc. 20, 277-300 (1983).

14. Heiner, R.A. Am. Econ. Rev. 73, 560-595 (1983).

15. Schindel, D.E. Paleobiology 8, 340-353 (1982).

16. Mayr, E. et al. Nature 296, 608-612 (1982).

17. Thompson, P. Phil. Sci, 50, $432-452$ (1983).

18. Smith, J. A. A. Rev. Genet 17,11-25 (1983).

19. Willi, J.M. A. Rev Gener. 17, 11-25 (1983)

20. Hoffman, A. Pol. Tow. Geol, 48, 327-331 (1978).

21. Temple, J.T. Lethaia 11, 340, (1978).

22. Slatkin, M. Paleobiology 7, 421-425 (1981)

23. Ginzburg, L.R. Paleobiology 7, 426-429 (1981).

24. Biebricher, C.K. Evolut. Biol. 16, 1-52 (1983).

25. Ricklefs, R.E. Paleobiology 6, 271-275 (1980).

26. McDonald, J.F. A. Rev. Ecol. System. 14, 77-102 (1983)

27. Jablonski, D., Sepkoski, J.J., Bottjer, D.J. \& Sheehan, P.M. Science 22, $1123-1125$ (1983).

28. Simpson, G.G. Tempo and Mode in Evolution (Columbia University Press, New York, 1944).

\section{Seminal lymphocytes, plasma and AIDS}

SIR - It has been suggested that cells or soluble agents in semen might induce immunosuppression following passage through rectal mucosal monolayers into lymphatics or blood vessels after injury during passive anal intercourse ${ }^{1,2}$. And the relatively great thickness of the vaginal mucosa has been put forward to explain the relatively low incidence of acquired immune deficiency syndrome (AIDS) in US women not transfused or using drugs ${ }^{2}$. Emphasizing the remarkable emperipoletic (Gr. em, in - peri, around - polesis, wandering about $)^{3,4}$ motility of small lymphocytes, others ${ }^{5,6}$ suggested that seminal lymphocytes infected with lymphotropic retroviruses might transfect AIDS relatively easily through the thin rectal mucosa, with or without injury. Passage through seems confirmed experimentally by finding antilymphocyte antibodies in healthy male rabbits given semen via anal catheterization from others with or without vasectomy ${ }^{7}$.

Through such emperipoletic lymphocyte transfection one might explain immune abnormalities in a woman routinely engaging in anal intercourse ${ }^{8}$, as well as the relatively high incidence of AIDS in Haitian women 